\title{
The Relationship between Serum Procalcitonin and Dialysis Adequacy in Hemodialysis Patients
}

\author{
Khaled Gouda ${ }^{*}$, Saeed Abdelwahab Saeed, Ahmed Yehia Mohamed
}

Division of Nephrology Department of Internal Medicine, Faculty of Medicine, Ain Shams University, Cairo, Egypt *Corresponding author: Khaled Gouda, Mobile: (+20)1111990962, E-Mail: khaled.gouda@med.asu.edu.eg@gmail.com

\begin{abstract}
Introduction: In hemodialysis (HD) patients procalcitonin (PCT) considered as an early predictor of acute infection. It represents a new and potential marker of inflammation and may correlate with dialysis adequacy. This makes procalcitonin a potential biomarker for obesity-related low-grade inflammation.

Objective: The aim of the work was to assess procalcitonin level in obese prevalent hemodialysis patients and its relation to hemodialysis adequacy.

Patients and Methods: A cross sectional study was conducted on 90 patients divided into 3 groups, 40 obese (BMI $\geq$ $30 \mathrm{Kg} / \mathrm{m} 2$ ) ESRD patients on regular hemodialysis (group A), 40 non obese (BMI $<25 \mathrm{Kg} / \mathrm{m} 2$ ) ESRD patients on regular hemodialysis (group B) attending at Dialysis Unit, El-Sahel Teaching Hospital and 10 healthy individuals with BMI $<25 \mathrm{Kg} / \mathrm{m} 2$ as a control group (group C). All patients were subjected to detailed history taking and general examination. All patients were laboratory investigated for CBC, serum urea, creatinine, CRP, urea reduction ratio (URR), equilibrated $\mathrm{Kt} / \mathrm{v}$. All controls were subjected to written informed consent, full history, examination and CRP level. Procalcitonin level was done by ELISA technique for all patients and controls.

Results: In our study, we found that there was a higher level of procalcitonin (PCT) in obese hemodialysis patient than non-obese. We also found that there was no correlation between PCT and hemodialysis adequacy in our study population.
\end{abstract}

Conclusion: It could be concluded that procalcitonin is a potential biomarker for obesity-related low-grade inflammation, but not related to hemodialysis adequacy.

Keywords: Hemodialysis, Procalcitonin, Obesity.

\section{INTRODUCTION}

Procalcitonin (PCT) is an innovative and highly specific marker for the diagnosis of clinically relevant bacterial infections and sepsis. It is a marker of inflammatory response stimulated by production of bacterial endotoxins and cytokines (IL-1, IL-6, and TNF) (1).

Large number of publications, primarily clinical studies, demonstrated the increasing use of Procalcitonin (PCT) in modern clinical practice. It is a propeptide of calcitonin induced by a variety of stimuli including bacterial endotoxins, pro-inflammatory cytokines and triggering events such as trauma or cardiogenic shock. PCT is not induced by viral infections, autoimmune disorders, neoplastic diseases, and organs transplantation ${ }^{(2)}$.

In healthy people, PCT Level is very low, usually $0.1 \sim 0.5 \mathrm{ng} / \mathrm{L}$. In the case of infection, PCT appeared and increased earlier than CRP, IL- 6 and other acute proteins and inflammatory factors, and the half-life was shorter, so PCT had higher sensitivity and specificity. Animal studies have found that injection of IL-6 and TNF- $\alpha$ in a rat model of sepsis can cause large-scale release and increase of PCT, and PCT itself has no significant effect on the increase of cytokines, PCT can be a secondary inflammatory factor and amplify the inflammatory effect ${ }^{(\mathbf{3})}$.

The serum PCT level of non-infected patients with chronic kidney disease (CKD), including dialysis, is significantly higher than that of healthy people ${ }^{(4)}$.
Herget-Rosenthal and his colleagues reported that the PCT level gradually increased according to the degree of deterioration in renal function and was influenced by the type of the renal replacement therapy (5).

Uremia has various influences on the general condition of patients with ESRD (6). Inflammatory cytokines produced and released by uremia cause chronic inflammation in the whole body. The activation of TNF-alpha, an inflammatory cytokine, is well known to promote PCT production ${ }^{(7)}$.

A significant number of patients who undergo hemodialysis are overweight or obese ${ }^{(8)}$. The presence of excess weight, especially visceral obesity contributes to the increased risk of metabolic and cardiovascular complications in patients with chronic kidney disease (CKD). The relationship between weight and outcome is complex among dialysis patients. The extra weight is usually associated with improved survival in this patient group ${ }^{(9)}$.

Some studies showed that adipose tissue is capable of expressing and secreting procalcitonin (10). Despite constant efforts to improve the survival of hemodialysis (HD) patients, which have produced tangible results, their mortality rate remains high Several factors affect survival in HD patients, with dialysis adequacy representing one of the most important and modifiable factors (11). Procalcitonin (PCT) represents a new and potential marker of 
inflammation and may correlate with dialysis adequacy (12).

The aim of the current work was to assess procalcitonin level in obese prevalent hemodialysis patients and its relation to hemodialysis adequacy.

\section{PATIENTS AND METHODS}

A cross sectional study was conducted on 90 patients divided into 3 groups, 40 obese (BMI $\geq 30$ $\mathrm{Kg} / \mathrm{m} 2)$ ESRD patients on regular hemodialysis (group A), 40 non obese (BMI $<25 \mathrm{Kg} / \mathrm{m} 2)$ ESRD patients on regular hemodialysis (group B) attending at Dialysis Unit, El-Sahel Teaching Hospital and 10 healthy individuals with BMI $<25 \mathrm{Kg} / \mathrm{m} 2$ served as a control group (group C).

\section{Ethical approval:}

This study was performed in accordance with the ethical standards of Ain Shams University Research Committee and with the 1964 Helsinki declaration and its later amendments or comparable ethical standards. Written consent from included subjects and acceptance of the ethical committee.

All patients were older than 18 years, clinically stable ESRD patients on regular HD for at least 6 months, receiving 3 sessions /week, each session 4 hours with arteriovenous fistula (AVF).

Patients with dialysis catheters, active inflammation, infections, auto immune diseases, malignancies and terminal illness were excluded from our study.

All patients were subjected to full history taking and examination included cause of renal failure, duration of dialysis, dialysis prescription, associated medical comorbidities.
All patients were laboratory investigated for $\mathrm{CBC}$, serum urea, creatinine, $\mathrm{CRP}$, urea reduction ratio (URR), equilibrated Kt/v. All controls were subjected to written informed consent, full history and examination and CRP level. Procalcitonin level was done by ELISA technique for all patients and control.

\section{Statistical analysis}

Recorded data were analyzed using the statistical package for social sciences, version 20.0 (SPSS Inc., Chicago, Illinois, USA). Quantitative data were expressed as mean \pm standard deviation (SD). Qualitative data were expressed as frequency and percentage. The following tests were done: Independent-samples t-test of significance was used when comparing between two means. Paired sample ttest of significance was used when comparing between related samples. Chi-square (x2) test of significance was used in order to compare proportions between qualitative parameters. The confidence interval was set to $95 \%$ and the margin of error accepted was set to $5 \%$. $P$ value $<0.05$ was considered significant.

\section{RESULTS}

A cross sectional study was conducted on 90 patients divided into 3 groups: 40 obese ESRD patients on regular hemodialysis, BMI $\geq 30 \mathrm{Kg} / \mathrm{m}^{2}$, (group A), 40 non obese ESRD patients on regular hemodialysis, BMI $<25 \mathrm{Kg} / \mathrm{m}^{2}$, (group B), and 10 healthy individuals with BMI $<25 \mathrm{Kg} / \mathrm{m}^{2}$, as a control group (group C).

There was no statistically significant difference between groups as regard gender ( $\mathbf{p}$ value $>\mathbf{0 . 0 5}$ ), There was a statistically significant difference between 3 groups as regarding age ( $\mathbf{p}$ value $\leq \mathbf{0 . 0 5})$.

Table (1): Comparison between the three studied groups according to demographic data

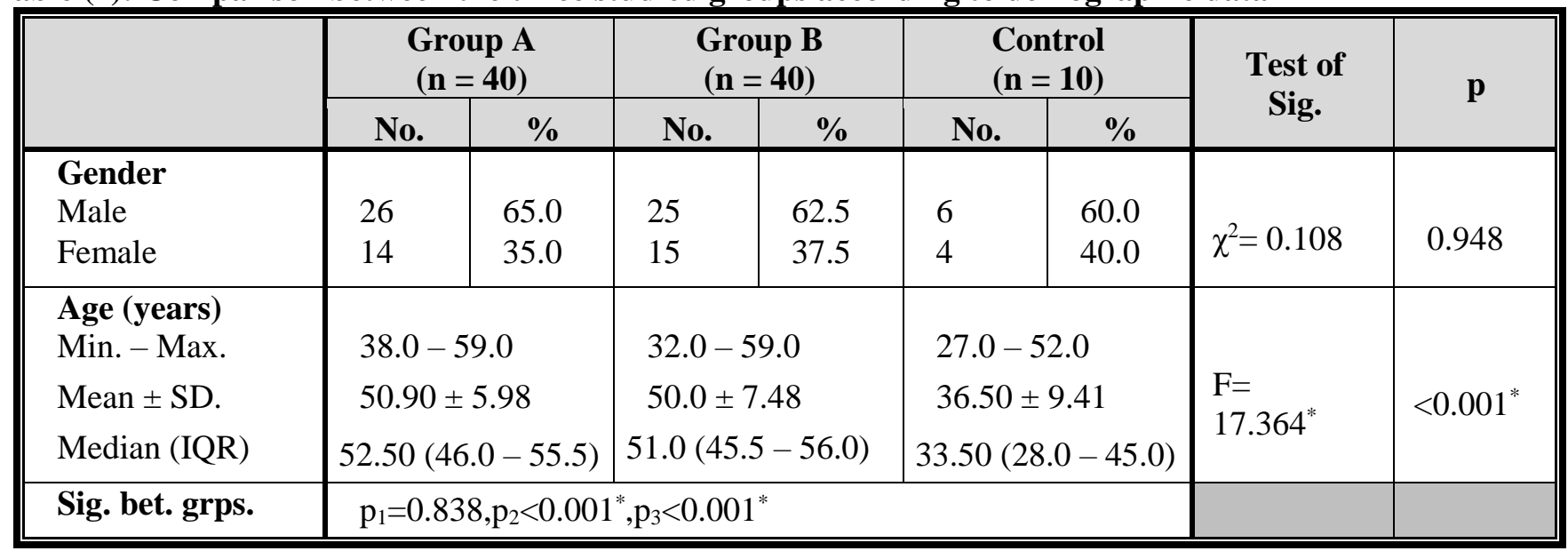

There was no a statistical significant difference between 3 groups as regarding sex, $\mathrm{p}$ value $>0.05$. There was a statistical significant difference between 3 groups as regarding age, $\mathrm{p} \leq 0.05$. 
Table (2): Comparison between the two studied groups according to cause of Renal failure (RF) and duration of HD (years)

\begin{tabular}{|c|c|c|c|c|c|c|}
\hline & \multicolumn{2}{|c|}{ Group A $(n=40)$} & \multicolumn{2}{|c|}{ Group B $(n=40)$} & \multirow{2}{*}{$\chi^{2}$} & \multirow{2}{*}{${ }^{\mathrm{MC}} \mathbf{p}$} \\
\hline & No. & $\%$ & No. & $\%$ & & \\
\hline Cause of RF & & & & & \multirow{8}{*}{6.150} & \multirow{8}{*}{0.351} \\
\hline DM & 2 & 5.0 & 6 & 15.0 & & \\
\hline HTN & 18 & 45.0 & 14 & 35.0 & & \\
\hline HTN - DM & 17 & 42.5 & 14 & 35.0 & & \\
\hline Obst. uropathy & 1 & 2.5 & 0 & 0.0 & & \\
\hline ADPKD & 2 & 5.0 & 4 & 10.0 & & \\
\hline Renal stones & 0 & 0.0 & 1 & 2.5 & & \\
\hline Amyloidosis & 0 & 0.0 & 1 & 2.5 & & \\
\hline $\begin{array}{l}\text { Duration of HD (years) } \\
\text { Mean } \pm \text { SD. } \\
\text { Median (IQR) }\end{array}$ & \multicolumn{2}{|c|}{$\begin{array}{c}4.30 \pm 1.64 \\
4.0(3.0-5.0)\end{array}$} & \multicolumn{2}{|c|}{$\begin{array}{c}4.53 \pm 1.54 \\
4.50(3.0-6.0)\end{array}$} & $t=0.634$ & 0.528 \\
\hline
\end{tabular}

There was no a statistical significant difference ( $\mathrm{P}$ value $>0.05)$ between groups $(\mathrm{A})$ and $(\mathrm{B})$ as regard cause of renal failure and duration of HD.

Table (3): Comparison between the three studied groups according to PCT

\begin{tabular}{||c|c|c|c|c|c||}
\hline PCT pg/ml & $\begin{array}{c}\text { Group A } \\
(\mathbf{n = 4 0})\end{array}$ & $\begin{array}{c}\text { Group B } \\
(\mathbf{n = 4 0 )}\end{array}$ & $\begin{array}{c}\text { Control } \\
(\mathbf{n = 1 0})\end{array}$ & F & p \\
\hline Mean \pm SD & $777.7 \pm 52.6$ & $194.8 \pm 16.4$ & $103.1 \pm 7.79$ & $243.265^{*}$ & $<0.001^{*}$ \\
\hline Sig. bet. grps. & \multicolumn{2}{|c|}{$\mathrm{p}_{1}<0.001^{*}, \mathrm{p}_{2}<0.001^{*}, \mathrm{p}_{3}=0.116$} & & \\
\hline
\end{tabular}

There was a highly statistical significant difference $(\mathrm{P}$ value $<0.01)$ between group $\mathrm{A}$ and group $\mathrm{B}$ regarding the procalcitonin level (PCT).and there is statistical significant difference (P value $<0.01)$ between group A and group C. there is no statistical significant difference between group B and group $\mathrm{C}$.

Table (4): Correlation between PCT with different parameters in each group

\begin{tabular}{|c|c|c|c|c|c|c|}
\hline & \multicolumn{6}{|c|}{$\overline{P C T}$} \\
\hline & \multicolumn{2}{|c|}{ Group A } & \multicolumn{2}{|c|}{ Group B } & \multicolumn{2}{|c|}{ Control } \\
\hline & $\mathbf{r}$ & $\mathbf{p}$ & $\mathbf{r}$ & $\mathbf{p}$ & $\mathbf{r}$ & $\mathbf{p}$ \\
\hline Age (years) & -0.252 & 0.117 & 0.072 & 0.658 & -0.306 & 0.390 \\
\hline Duration of HD (years) & 0.013 & 0.937 & 0.222 & 0.168 & - & - \\
\hline Dry Weight (kg) & 0.220 & 0.173 & 0.241 & 0.134 & 0.394 & 0.326 \\
\hline Height $(\mathrm{cm})$ & -0.088 & 0.589 & 0.099 & 0.542 & 0.696 & $0.025^{*}$ \\
\hline BMI $\left(\mathrm{kg} / \mathrm{m}^{2}\right)$ & 0.244 & 0.130 & 0.148 & 0.362 & 0.381 & 0.278 \\
\hline Waist circumference $(\mathbf{c m})$ & 0.067 & 0.683 & 0.031 & 0.848 & 0.458 & 0.183 \\
\hline CRP (mg/L) & -0.154 & 0.342 & -0.102 & 0.533 & 0.419 & 0.228 \\
\hline IDWG (kg) & 0.052 & 0.748 & -0.019 & 0.907 & - & - \\
\hline Systolic & -0.105 & 0.521 & 0.097 & 0.552 & 0.244 & 0.130 \\
\hline Diastolic & 0.028 & 0.864 & 0.297 & 0.063 & 0.148 & 0.362 \\
\hline URR & 0.097 & 0.552 & 0.023 & 0.888 & - & - \\
\hline $\mathbf{K t} / \mathbf{V}$ & 0.134 & 0.410 & 0.031 & 0.848 & - & - \\
\hline Urea pre (mg/dl) & 0.279 & 0.081 & -0.030 & 0.853 & - & - \\
\hline Urea Post (mg/dl) & 0.172 & 0.288 & -0.032 & 0.845 & - & - \\
\hline Creatinine (mg/dl) & 0.054 & 0.742 & -0.043 & 0.793 & - & - \\
\hline HB (g/dl) & 0.212 & 0.190 & -0.149 & 0.357 & - & - \\
\hline HCT (\%) & 0.253 & 0.115 & -0.206 & 0.202 & - & - \\
\hline RBCs (millions/cmm) & 0.097 & 0.551 & -0.033 & 0.841 & - & - \\
\hline WBCs $(\mathbf{x 1 0} /$ ul $)$ & 0.035 & 0.829 & -0.104 & 0.523 & - & - \\
\hline PLT $\left(\times 10^{3} / \mathrm{ul}\right)$ & 0.212 & 0.190 & -0.002 & 0.993 & - & - \\
\hline
\end{tabular}

There were a statistical significant difference $(\mathrm{P}$ value $<0.05)$ between procalcitonin $(\mathrm{PCT})$ and height group (C). And there was no a statistical significant difference between procalcitonin (PCT) and the other parameters in each group. 


\section{DISCUSSION}

In our study, there was a statistical significant difference between 3 groups regarding the mean of age, procalcitonin (PCT) level, blood urea. However there was no a statistical significant difference between 3 groups regarding the mean of sex, height, HB, WBCs, PLT, Creatinine, and CRP.

There was no a statistical significant difference between groups (A) and (B) as regard URR, Kt/V and the cause of renal failure, duration of hemodialysis

In our study, we found that there was a statistically significant difference $(\mathrm{P}$ value $<0.01)$ between group $\mathrm{A}$ and group B regarding the procalcitonin level (PCT) as it increased - within the normal range - in group A.

We also found no correlation between procalcitonin and the body mass index in the three groups. This could be explained as circulating levels of procalcitonin are related to adipocyte function rather than mass. This comes in agree with Baghi et al. ${ }^{\left({ }^{(13)}\right.}$ who studied serum procalcitonin level in febrile patients in emergency ward. Also, it goes in line with the findings of El-Ballat et al. ${ }^{(14)}$ who studied procalcitonin level in obese chronic hemodialysis patients and reported that procalcitonin was independent on the body mass index.

This is in contrary to Abbasi et al. ${ }^{\left({ }^{(5)}\right.}$ who studied whether plasma procalcitonin is associated with obesity, insulin resistance, and the metabolic syndrome and found that PCT increased gradually - within the normal range -with the increase in body mass index and procalcitonin levels were attenuated after adjustment for BMI.

In our study PCT was not dependent on waist circumference in the three groups ( $\mathrm{p}$ value $>0.05$ ). This comes in line with El-Ballat et al. ${ }^{(14)}$ who found that PCT was not dependent on waist circumference.

On the other hand Abbasi et al. ${ }^{(15)}$ showed that PCT increased gradually -within the normal rangeaccording to increase in mean of waist circumference.

Our study revealed that there was no significant correlation between PCT and body weight in the three groups $(\mathrm{P}=0.173$ and $\mathrm{r}=0.220$ in group $\mathrm{A}, \mathrm{P}=0.134$ and $r=0.241$ in group $\mathrm{B}, \mathrm{P}=0.326$ and $\mathrm{r}=0.394$ in group $\mathrm{C}$ ).

These results go in agreement with Kim et al. ${ }^{(16)}$ who studied the correlation of Glasgow prognostic score and procalcitonin with clinical variables in patients with pretreatment lung cancer and reported no statistically significant relationship between procalcitonin levels and body weight.

Our study showed that procalcitonin levels is not related to the patients 'age which comes in agree with Baghi et al. ${ }^{(13)}$ who reported that PCT IS not correlated with age. They studied cases only who had infection.

This is in contrary to Abbasi et al. ${ }^{(15)}$ who found that procalcitonin level increased with age and this may be explained as the process of aging is associated with increase in the release of cytokines which in turn increases the release of PCT.

Also, our results revealed that there was no significant correlation between PCT and duration of HD in group A and group B which comes in agree with
Ichihara et al. ${ }^{(17)}$ and El-Ballat et al. ${ }^{(14)}$ who found no correlation between them.

Concerning systolic and diastolic blood pressure, our study showed no correlation between blood pressure and PCT which comes in agree with Ichihara et al. ${ }^{(17)}$ who studied the procalcitonin level in chronic hemodialysis patients with no evidence of bacterial infection.

Concerning height, our study found no correlation between it and PCT and this come in agree with ElBallat et al. ${ }^{(14)}$ and in contrary to Baghi et al. ${ }^{(13)}$ who showed a strong correlation between height and PCT (P value 0.001 ).

In our study, no significant correlation was found between PCT and WBCs count, RBCs count and hemoglobin level, our results agree with Abedini $\boldsymbol{e}$ al . (18) and El-Ballat et al. ${ }^{(14)}$ who studied procalcitonin level in chronic hemodialysis patients with obesity,but disagree with Çelik $\boldsymbol{e t}$ al. ${ }^{\left({ }^{19)}\right.}$ who found statistical difference between them.

We found no statistically significant difference between PCT and sex in our study, and this agree with Koido et al. ${ }^{(20)}$.

Also, we found no statistically significant correlation between PCT and CRP, our results agree with Dahaba et al. ${ }^{(21)}$ who studied procalcitonin and Creactive protein plasma concentrations in nonseptic uremic patients undergoing hemodialysis who showed that hemodialysis had no significant effect on CRP concentration, making CRP a possible useful marker of sepsis in these patients.

There is no statistically significant correlation between PCT and blood urea level in group a and group $\mathrm{b}$ in our study as in Kim et al. ${ }^{(16)}$.

Our study also showed no statistically significant correlation between PCT and hemodialysis adequacy. This agrees with Mukda et $\boldsymbol{a l} .{ }^{(12)}$ who reported no correlation between plasma levels OF dialysis appearance rate (AR) of vascular endothelial growth factor (VEGF), IL-6, and Procalcitonin with dialysis adequacy.

Wang and et al. (22) studied the relationship between serum procalcitonin and dialysis adequacy in peritoneal dialysis patients and reported negative correlations between PCT and hemodialysis adequacy.

No available current studies were recorded discussing our studied relationship between PCT and obese hemodialyzed patients and its relation to hemodialysis adequacy to be compared with our results, however we did it as a first step in research study in our community to study the level of procalcitonin in obese hemodialysis patients and its relation to hemodialysis adequacy.

\section{CONCLUSION}

It could be concluded that procalcitonin is a potential biomarker for obesity-related low-grade inflammation. But not related to hemodialysis adequacy. 
Financial support and sponsorship: Nil.

Conflict of interest: Nil.

\section{REFERENCES}

1. Becker K, Richard S, Eric S (2008): Procalcitonin assay in systemic inflammation, infection, and sepsis: clinical utility and limitations. Critical Care Medicine, 36: 941-52.

2. Richard P, Bigham M, Giuliano J (2014): Use of procalcitonin for the prediction and treatment of acute bacterial infection in children. Current Opinion in Pediatrics, 26: 292-98.

3. Fu Y, Chen J, Cai B et al. (2012): The use of PCT, CRP, IL-6 and SAA in critically ill patients for an early distinction between candidemia and Gram positive/negative bacteremia. J Infect., 64(4): 438-40.

4. Trimarchi H, Dicugno M, Muryan A et al. (2013): Pro-calcitonin and inflammation in chronic hemodialysis. Medicina (B Aires), 73(5): 411-6.

5. Herget-Rosenthal $\mathrm{S}$, Klein $\mathrm{T}$, Marggraf $\mathrm{G}$ et al. (2005): Modulation and source of procalcitonin in reduced renal function and renal replacement therapy. Scand J Immunol., 61:180-6.

6. Bergstrom J, Lindholm B (1999): Malnutrition, cardiac disease, and mortality. Perit Dial Int., 19(2): 309-14.

7. Foushee J, Hope N, Grace $\mathbf{E}$ (2012): Applying biomarkers to clinical practice: aguide for utilizing procalcitonin assays. J Antimicrob Chemother., 67:2560-9.

8. Shao-Yu Y, Chiang C, Hsu S et al. (2007): Metabolic syndrome predicts hospitalization in hemodialysis patients: a prospective Asian cohort study. Blood purification, 25: 252-59.

9. Panzetta G, Abaterusso C (2010): Obesity in dialysis and reverse epidemiology: True or false? G Ital Nefrol., 27(6):629-38.

10. Philippe L, Seboek D, Zulewski H et al. (2005): Autocrine/paracrine role of inflammation-mediated calcitonin gene-related peptide and adrenomedullin expression in human adipose tissue. Endocrinology, 146: 2699-708.

11. Van Tuyen D, Wu P, Wong T et al. (2019): Mid-arm circumference, body fat, nutritional and inflammatory biomarkers, blood glucose, dialysis adequacy influence all-cause mortality in hemodialysis patients: A prospective cohort study. Medicine (Baltimore), 98(12): 14930-34.
12. Mukda B, Sathit K, Thananda T (2019): Interleukin6, procalcitonin, and vascular endothelial growth factor in plasma and dialysate correlate with dialysis adequacy in continuous ambulatory peritoneal dialysis patients. Clin Nephrol., 92(5):273-275.

13. Baghi H, Attari Z, Farzmehdi M et al. (2015): Evaluation Serum Procalcitonin Level in Febrile Patients in Emergency Ward. Int J Curr Microbiol App Sci., 4: 875-80.

14. El-Ballat M, Rashid E, Abd-Elraouf A (2019): Assessment of Procalcitonin Level in Chronic Hemodialysis Patients with Obesity. The Egyptian Journal of Hospital Medicine, 74 (2):388-395.

15. Abbasi A, Corpeleijn E, Postmus D et al. (2010): Plasma procalcitonin is associated with obesity, insulin resistance, and the metabolic syndrome. The Journal of Clinical Endocrinology \& Metabolism, 95: 26-31.

16. Kim Y, Seok J, Lee G et al. (2016): Correlation of Glasgow Prognostic Score or Procalcitonin to Clinical Variables in Patients with Pretreatment Lung Cancer. Biomedical Science Letters, 22: 9-17.

17. Ichihara K, Tanaka T, Takahashi S et al. (2016): Serum procalcitonin level in chronic hemodialytic patients with no evidence of bacterial infection. Renal Replacement Therapy, 2: 9-13.

18. Abedini M, Delpisheh A, Nikkhu B et al. (2012): Procalcitonin and white blood cell count (WBC), erythrocyte sedimentation rate (ESR) and serum Creactive protein (CRP) alterations in children with systemic inflammatory response syndrome before and after treatment. African Journal of Biotechnology, 11: 10989-93.

19. Çelik H, Portakal O, Yiğit S et al. (2016): Efficacy of new leukocyte parameters versus serum C-reactive protein, procalcitonin, and interleukin- 6 in the diagnosis of neonatal sepsis. Pediatrics International, 58: 119-25.

20. Koido S, Ohkusa T, Takakura K et al. (2013): Clinical significance of serum procalcitonin in patients with ulcerative colitis. World Journal of Gastroenterology, 19: 8335-39.

21. Dahaba A, Rehak P, List W (2003): Procalcitonin and C-reactive protein plasma concentrations in nonseptic uremic patients undergoing hemodialysis. Intensive Care Med., 29:579-583.

22. Wang B, Gao C, Chen Q et al. (2021): The Relationship between Serum Procalcitonin and Dialysis Adequacy in Peritoneal Dialysis Patients. Iran J Public Health, 50: 502-509. 